\title{
NopA Is Associated with Cell Surface Appendages Produced by the Type III Secretion System of Rhizobium sp. Strain NGR234
}

\author{
William J. Deakin, ${ }^{1}$ Corinne Marie, ${ }^{1}$ Maged M. Saad, ${ }^{1}$ Hari B. Krishnan, ${ }^{2}$ and William J. Broughton ${ }^{1}$ \\ ${ }^{1}$ LBMPS, Département de Biologie Végétale, Sciences III, 30 Quai Ernest-Ansermet, University of Geneva, $\mathrm{CH}-1211$ \\ Geneva 4, Switzerland; ${ }^{2}$ Plant Genetics Research Unit, United States Department of Agriculture-Agricultural Research \\ Service and Department of Agronomy, University of Missouri, Columbia 65211, U.S.A.
}

Submitted 28 July 2004. Accepted 17 December 2004.

\begin{abstract}
Rhizobium sp. strain NGR234, which is capable of interacting with a large number of legumes, utilizes a variety of signaling molecules to establish nitrogen-fixing symbioses. Among these are nodulation outer proteins (Nops) that transit through a type III secretion system (TTSS). Abolition of Nop secretion affects nodulation of certain legumes. Under free-living conditions, the secretion of Nops can be induced by the addition of flavonoids. Here, we show that an in-frame deletion of nopA abolishes secretion of all other Nops and has the same impact on nodule formation as mutations that lead to a nonfunctional TTSS. This secretionminus phenotype of the nopA mutant, as well as bioinformatics analysis of NopA itself, suggests that NopA could be an external component of the TTSS. Electron microscopy showed that NGR234 synthesizes fibrillar structures on the cell surface in a flavonoid-inducible and NopA-dependent manner. Purification of the macromolecular surface appendages revealed that NopA is a major component of these structures.
\end{abstract}

Additional keywords: effector, pathogenicity, pilus, translocator.

Rhizobia have the ability to induce the formation of (and colonize) root nodules on leguminous plants. Once within nodules, rhizobia reduce atmospheric nitrogen to ammonia, which is taken up by the host plant in exchange for photosynthates. Nodule development requires a complex exchange of signals between both organisms. Initially, flavonoids exuded by root cells induce a number of bacterial genes. This induction is mediated by the transcriptional regulator NodD1, which binds to conserved sequences (nod boxes) found within the promoter regions of various genes required for the symbiosis. The earliest detected bacterial signal molecules are Nod factors, which are synthesized and secreted by all rhizobia and are essential for nodule formation (Broughton et al. 2000; Perret et al. 2000). There are a number of other molecules produced by rhizobia that are involved in later stages of nodule formation, bacterial entry, and nitrogen fixation. Not all of these molecules are ubiquitous, however; some are specific to certain rhizobial strains where they determine

Corresponding author: W. J. Broughton, Telephone: +41 22379 3108/9; Fax: +41 22379 3009; E-mail: william.broughton@bioveg.unige.ch

Current address of C. Marie: Unité de Génétique Microbienne, INRA, Domaine de Vilvert, 78352 Jouy en Josas, France. the host range. Proteins secreted by the type III secretion system (TTSS) of Rhizobium sp. strain NGR234 (hereafter called NGR234) are part of such a signaling system. The TTSS of NGR234 was discovered after sequencing of the symbiotic plasmid, pNGR234a, which contains many of the loci required for nodulation (Freiberg et al. 1997). Type III secretion is a common virulence mechanism of many pathogenic bacteria of plants and animals that inject proteins synthesized within the bacteria into eukaryotic cells (He 1998; Hueck 1998). It is the action of these "effector" proteins within the eukaryotic cell, often by interfering with signal transduction cascades, which contributes to the pathogenicity of the infecting bacteria (Büttner and Bonas 2003). TTSSs have now been identified in a number of rhizobial strains (Marie et al. 2001) as well as in other symbiotic bacteria (Dale et al. 2001). In NGR234, the TTSS is under flavonoid/ NodD1 control via the nod box of TtsI (Kobayashi et al. 2004), a transcriptional activator known to be required for nodulation outer protein (Nop) secretion (Viprey et al. 1998). Another putative cis element (called a tts box) has been found in the promoter regions of the genes encoding components of rhizobial TTSSs, and it is postulated that TtsI acts via these $t$ ts boxes to bring about TTSS gene induction (Krause et al. 2002). NGR rhcN, a TTSS mutant of NGR234, was used to demonstrate the role of the TTSS in nodulation. Nodulation of two plant species (Pachyrhizus tuberosus and Tephrosia vogelii) is affected by the presence or absence of a functional TTSS, whereas other species (e.g., Lotus japonicus, Leucaena leucocephala, and Vigna unguiculata) barely respond to the mutant (Viprey et al. 1998). Further studies have shown that proteins secreted by the TTSS affect the nodulation capability of NGR234 on other legume species (Marie et al. 2003). Recently, mutagenesis of the TTSSs of Rhizobium fredii USDA257 (hereafter called USDA257) and Bradyrhizobium japonicum 110spc4 (USDA110) demonstrated their roles in nodulation of other legumes (Krause et al. 2002; Krishnan et al. 2003).

TTSSs are encoded by a family of conserved genes that are thought to be involved in the synthesis of the core secretion machine. These genes encode proteins that form a complex spanning the bacterial membranes, as well as a cytoplasmic ATPase that is thought to energize the secretion process. Mutation of any of these genes blocks secretion (Cornelis and Van Gijsegem 2000). Not all of the secreted proteins function (as effectors) within eukaryotic cells. Some are external components of the secretion machine, while others have translocatory roles (i.e., they are required for the transit of the effectors 
through the eukaryotic plasma membrane) (Büttner and Bonas 2002). External components of the TTSS take the form of filamentous surface appendages and are described as needle-like structures in mammalian pathogens and as Hrp pili in phytopathogens (He and Jin 2003). Mutation of genes encoding the needle or pili subunits also blocks TTSS-dependent protein secretion (He and Jin 2003). Hrp pili have been visualized in three phytopathogens, Pseudomonas syringae, Ralstonia solanacearum, and Erwinia amylovora (Jin et al. 2001; Roine et al. 1997b; Van Gijsegem et al. 2000). Elegant studies have shown that the Hrp pili serve as conduits for the translocation of effector proteins across the plant cell wall (Brown et al. 2001; Jin and He 2001; Li et al. 2002).

Proteins secreted by the TTSS of rhizobia are called Nops, and two were identified initially (Marie et al. 2001; Viprey et al. 1998). Based upon their homology to other secreted proteins and the effects of mutations within the genes encoding them, possible functions have been assigned. NopX is thought to be a translocatory protein, whereas NopL is probably an effector that functions within legume root cells (Marie et al. 2003). NopL can be phosphorylated by plant protein kinases (Bartsev et al. 2003). We reason that, after translocation into plant cells, NopL probably interferes with plant signal-transduction cascades that are responsible for the induction of plant defense genes, because these are suppressed in transgenic plants that express nopL (Bartsev et al. 2004). Another putative effector, NopP, was identified using phage-display techniques (Ausmees et al. 2004). Experiments designed to find low molecular weight Nops showed that two other proteins, p19 and p10 (= NopC), were also secreted in a TTSS-dependent fashion. NopA, a 7-kDa protein, is found in all rhizobia that possess a TTSS, suggesting that it could be a conserved secreted component of the machinery or an important effector molecule (Marie et al. 2003).

\section{RESULTS}

Description of the nopA locus and identification of nopC.

Due to its small size, nopA was not identified during the sequencing of pNGR234a (Freiberg et al. 1997). Re-analysis of the TTSS locus revealed the presence of the gene that encodes NopA 106 bp upstream of $y 4 y Q$, a predicted open reading frame (ORF) encoding a protein of unknown function (Fig. 1). Homologues of nopA are found in similar positions (i.e., directly upstream of $\mathrm{y} 4 \mathrm{yQ}$ ) in the TTSS loci of USDA257, Mesorhizobium loti MAFF303099, and USDA110. A putative $t t s$ box approximately $450 \mathrm{bp}$ upstream of nopA had been detected (Krause et al. 2002) and within this region, 71 bp upstream of nopA, is another short ORF (part of which previously was annotated as fy1) that we have renamed $n o p C$. Because nopA and nopC were not characterized by Freiberg and associates (1997), we have updated the relevant GenBank entry (NC000914) to include them.

The predicted size of NopC is $10 \mathrm{kDa}$ and database searches reveal homology only to ORFs from other TTSS-possessing rhizobia (Fig. 2). Homologues of nopC are found (un-annotated) in the same position, relative to nopA, in the TTSS loci of USDA257 and MAFF303099. It is present (annotated as ORF id211) within the $t$ ts locus of USDA110, approximately 4 kbp upstream of nopA (Göttfert et al. 2001). The NopC homologues of MAFF303099 and USDA110 share 51 and 42\% identity at the amino acid level, respectively. The USDA257 ORF has a number of frame shifts in the coding region that extend the ORF, but the identity to NopC of NGR234 is still approximately $70 \%$ overall.

A TTSS-dependent secreted protein of approximately 10 $\mathrm{kDa}$ (designated p10) was observed in earlier studies (Marie et al. 2003); therefore, we speculated that it might be encoded by

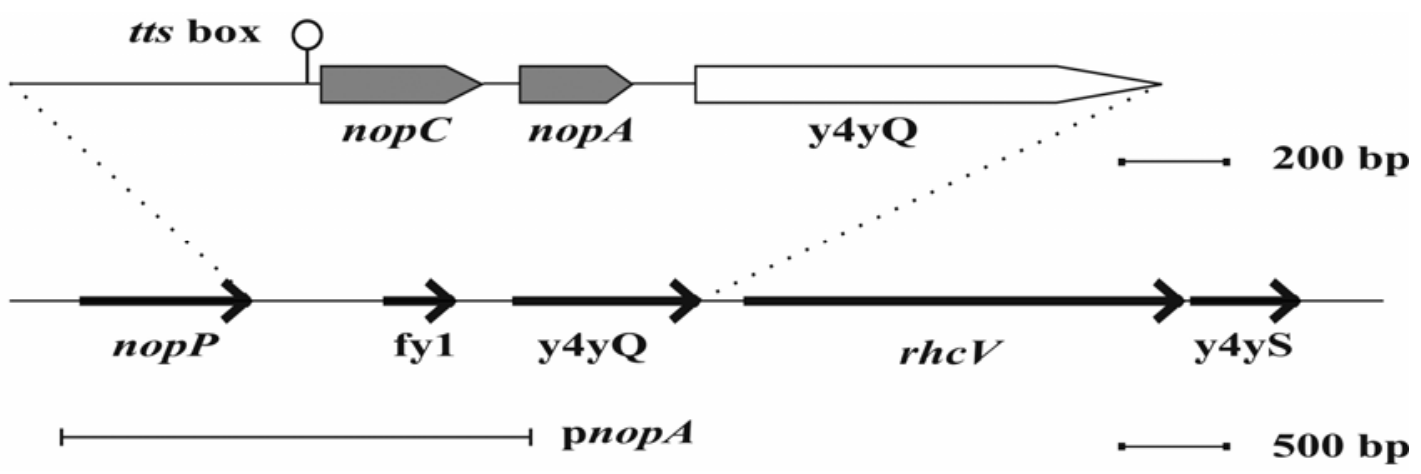

Fig. 1. Position of nopA within the type III secretion system (TTSS) locus of NGR234. The upper line shows the position of the newly annotated open reading frames (ORFs), nopC and nopA, upstream of y4yQ. Scaled down below it are the relative locations of the ORFs within the TTSS locus and the original annotation of $n o p C$ as fy1. The lowest bar represents the region cloned into pLAFR6 to form pnopA, which was used to complement NGR $\Delta n o p A$.
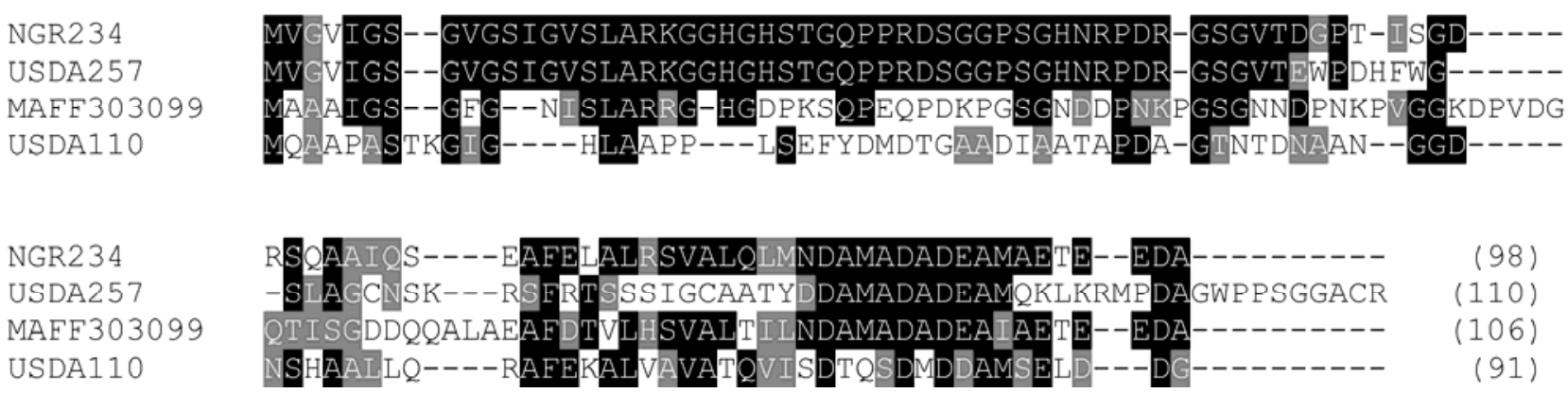

Fig. 2. Alignment of NopC amino acid sequences of various rhizobial strains. NopC homologues were identified only in the following rhizobia: Rhizobium sp. NGR234, R. fredii USDA257, Mesorhizobium loti MAFF303099, and Bradyrhizobium japonicum USDA110. Proteins were aligned using the ClustalW program and manipulated with Boxshade at EMBnet. Dark and gray boxes indicate identical and similar amino acids, respectively. The numbers in brackets at the end of each sequence refer to the length of the respective NopC homologue. 
nopC. Accordingly, supernatant proteins were extracted from cultures of NGR234 or NGR $2 r h c N$ and separated by twodimensional sodium dodecyl sulfate polyacrylamide gel electrophoresis (2D-SDS-PAGE) (Fig. 3A). A single spot of approximately $10 \mathrm{kDa}$ was clearly visible only in supernatants from NGR234, and its pI of approximately 4.8 is in good agreement with the theoretical pI of NopC (4.63). This spot was excised and digested with trypsin, and the tryptic fragments were subjected to peptide mass fingerprint analysis, which identified it as NopC. To confirm whether nopC might encode $\mathrm{p} 10$, an antibody was raised against synthetic peptides of the predicted amino-acid sequence of NopC. When tested against secreted protein preparations from NGR234 and NGR $\Omega r h c N$, the antibody specifically detected a protein of 10 $\mathrm{kDa}$ from NGR234 but not from NGR $2 r h c N$ or noninduced NGR234 (Fig. 3B). NopC was also secreted by strains mutated in genes encoding three of the other secreted Nops (NopL, P, and $\mathrm{X}$ ). Thus, nopC also encodes a secreted protein, which had been observed earlier as p10.

\section{Effect of a deletion of nopA on protein secretion and nodule formation.}

Three ORFs are downstream of nopA; y4yQ and y4yS encode putative proteins of unknown function (Fig. 1), whereas $r h c V$ specifies a conserved component of the TTSS. The intergenic gaps between all ORFs are relatively short and database searches do not reveal any obvious transcriptional signals within them. Thus, it is possible that the ORFs nopC-nopA$\mathrm{y} 4 \mathrm{yQ}-r h c V-\mathrm{y} 4 \mathrm{yS}$ are cotranscribed as an operon under the control of the tts box. Downstream of $y 4 y S$ is a sequence that could form a stem-loop structure and function as a transcriptional termination signal. Thus, it seems likely that polar mutation of nopA might also abolish transcription of the downstream genes, and the absence of RhcV (and possibly the proteins encoded by $\mathrm{y} 4 \mathrm{yQ}$ and $\mathrm{y} 4 \mathrm{yS}$ ) would probably block TTSS-dependent protein secretion, masking the function of NopA. To circumvent this problem, an in-frame deletion of nopA was created and used to generate a nonpolar mutation of nopA in NGR234. TTSS-dependent protein secretion was abolished in the NGR $\Delta$ nopA mutant (Fig. 4A). Antibodies raised against NopA, NopC, NopL, NopP, and NopX did not detect their respective antigens in supernatants of NGR $\Delta$ nopA cultures. This suggests that NopA, as well as being a secreted protein, is also required for the secretion of the other Nops.

To complement NGR $\triangle$ nopA, a plasmid containing nopA and the upstream tts box was supplied in trans (pnopA) (Fig. 1). pnopA contains the entire nopP-nop $C$ intergenic region with the associated tts box (and any other promoter elements) as well as nopA itself but not the ORFs downstream of nopA. This means that, if $\mathrm{y} 4 \mathrm{yQ}, r h c V$, or $\mathrm{y} 4 \mathrm{yS}$ were affected in NGR $\triangle$ nopA, they should not be complemented by pnopA. Introduction of pnopA to NGR $\Delta$ nopA restored Nop secretion (Fig. 4A).

If NopA is required for the secretion of other Nops, it follows that these other Nops should accumulate in cells of NopA-deficient strains. To test this, antibodies were used to check lysates of cell pellets left over from the isolation of supernatant proteins. Approximately $5 \mu \mathrm{g}$ of total proteins were separated by SDS-PAGE, then Western blotted, before immunological detection with anti-Nop antibodies. Only NopL could be clearly detected in all bacterial strains (Fig. 4B). None of the other Nops (A, C, P, or X) were detected (data not shown). Accumulation of NopL within the cells (but not in the supernatants of NGR $\Omega r h c N$ and NGR $\Delta n o p A$ ) proves that mutation of NopA blocks Nop secretion. These data also demonstrate that the techniques used to isolate proteins from the supernatants do not cause lysis of the bacterial cells (Fig. 4A).
Secretion of all Nops is blocked in the NGR $\Delta$ nopA mutant; therefore, we suspected that its nodulation phenotype would resemble that of a strain which is incapable of secreting Nops (e.g., NGR $\Omega r h c N$ ). To test this hypothesis, NGR $\Delta$ nopA was used to inoculate the legumes used in earlier work (Viprey et al. 1998). Both NGR $\Omega r h c N$ and NGR $\Delta$ nopA provoked similar phenotypes on the range of plants tested (Table 1). L. leucocephala and $V$. unguiculata showed only very slight responses to the presence or absence of Nops. On T. vogelii, the absence of Nops was detrimental to nodulation and plants inoculated with

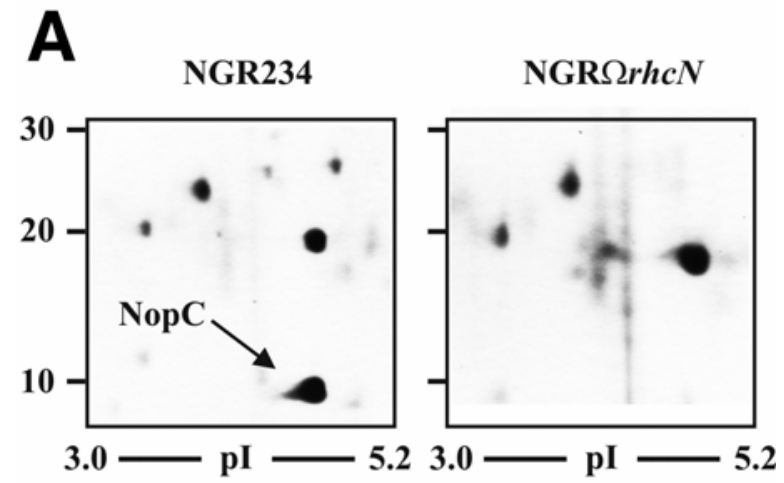

B

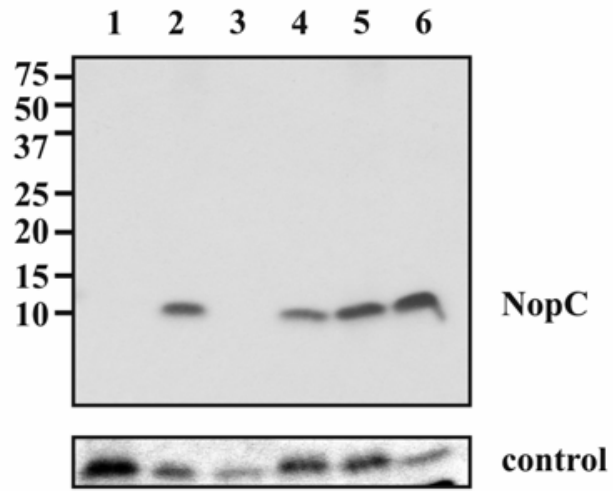

Fig. 3. Identification of NopC as a protein secreted via the type III secretion system of NGR234. A, Sections of two-dimensional sodium dodecyl sulfate polyacrylamide gel electrophoresis (SDS-PAGE) gels, stained with silver, containing extracted supernatant proteins from induced cultures of NGR234 (left box) and NGR $2 r h c N$ (right box). The numbers vertically marked against the boxes show the position of the size markers in $\mathrm{kDa}$. The $\mathrm{pI}$ range is shown beneath each box. In extractions from NGR234, a spot of approximately $10 \mathrm{kDa}$ and a pI of approximately 4.8 can be seen (labeled as NopC). The position of this spot fits well with the theoretical mass and $\mathrm{pI}$ of NopC, which are $9.8 \mathrm{kDa}$ and 4.6 , respectively. This spot was excised from the gels digested with trypsin, and the masses of the resulting peptides were determined by MALDI-TOF mass spectrometry. Four of the peptides had masses that matched those from NopC after an in silico trypsin digest. The identified peptides were MVGVIGSGVGSIGVSLARK, GSGVTDGPTISGDR, SQAAIQSEAFEL ALR, and GSGVTDGPTISGDRSQAAIQSEAFELAL, the final one being a composite of two smaller peptides probably resulting from incomplete trypsin digest of NopC. B, Supernatant proteins extracted from various NGR234 strains were separated on a 15\% SDS-PAGE gel and transferred by electroblotting to polyvinylidene difluoride membranes. Proteins isolated from the following strains were loaded in the following order; NGR234 (noninduced) (1), NGR234 (induced) (2), NGR $2 r h c N$ (induced) (3), NGR $\Omega$ nopL (induced) (4), NGR $\Delta$ nopP (induced) (5), and NGR $\Delta n o p X$ (induced) (6). Top box: the blot was probed with anti-NopC antiserum, and figures labeled vertically on the left-hand side show the position of the size markers. One band of approximately $10 \mathrm{kDa}$ can be seen in the

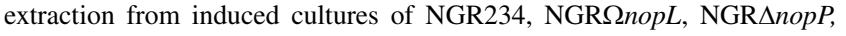
and NGR $\triangle$ nopX. The lower panel (control) was probed with anti-NopX antisera, which, in addition to NopX, also detects nonspecifically a supernatant protein found in extracts from all the tested strains. 
NGR $\triangle$ nopA had fewer nodules compared with those inoculated with the wild-type bacterium. Introduction of the complementing plasmid pnopA into the mutant restored nodulation to approximately wild-type levels. Conversely, on Pachyrhizus tube-

\section{A Supernatant}
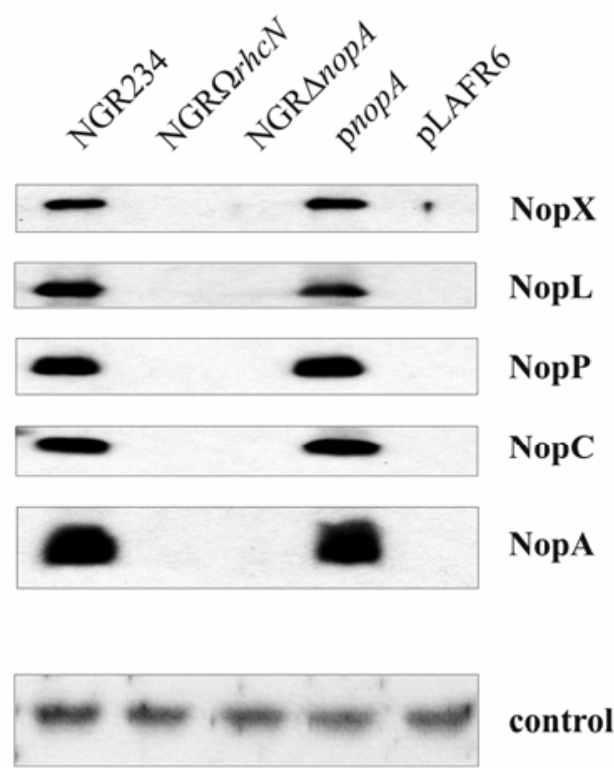

\section{B Lysate}

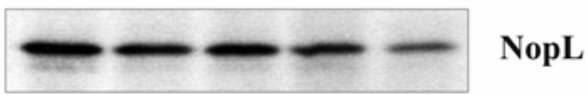

Fig. 4. A, Nodulation outer protein (Nop) secretion is blocked in the NopA minus mutant NGR $\Delta$ nopA. Secreted proteins were separated on 12 or $15 \%$ sodium dodecyl sulfate polyacrylamide gel electrophoresis, transferred to polyvinylidene difluoride membranes, and immunodetected using each of the Nop antibodies. All strains were induced by apigenin. The quantity of proteins loaded was normalized using a supernatant protein that the NopX antibody (labeled as control) detected nonspecifically. Extracts from NGR234 and NGR $\Omega r h c N$ were included as positive and negative controls, respectively. All five Nops were absent in the supernatants of NGR $\Delta$ nopA cultures. Complementation was achieved by the introduction of pnopA into NGR $\triangle$ nopA (the lane labeled "pnopA"). When the empty vector labeled "pLAFR6" was introduced into the nopA mutant, Nop secretion was not restored. B, Presence of Nops within the bacterial cells. The cells removed during the purification of the supernatant proteins were lysed and approximately $5 \mu \mathrm{g}$ were probed on immunoblots using the Nop antibodies. Only NopL could be detected specifically within the cells. rosus, abolition of Nop secretion promoted efficient nodulation, as had been observed previously (Viprey et al. 1998).

The only anomaly was seen when $P$. tuberosus roots were infected with NGR $\Delta$ nopA(pnopA); nodulation was equivalent to that obtained with a TTSS mutant although the introduction of pnopA into NGR $\Delta$ nopA had been shown to restore Nop secretion (Fig. 4A). We suspected that most of the bacteria might have lost the plasmid pnopA during the nodulation assay, thereby gaining a selective advantage to nodulate $P$. tuberosus. To test this, bacteria were re-isolated from $P$. tuberosus nodules and examined for sensitivity $\left(\mathrm{Tet}^{\mathrm{s}}\right)$ or resistance $\left(\mathrm{Tet}^{\mathrm{r}}\right)$ to tetracycline. As expected, all rhizobia isolated from $P$. tuberosus nodules provoked by the NGR $\Delta$ nopA(pnopA) transconjugants were $\mathrm{Tet}^{\mathrm{s}}$, indicating loss of pnopA and, thus, Nop secretion. In contrast, the bacteria isolated from the nodules induced by the control strain NGR $\Delta$ nopA(pLAFR6) were all Tet $^{\mathrm{r}}$, implying no plasmid loss and that pLAFR6 is stably maintained during nodule formation. Transconjugants harboring nopA are thus disadvantageous for nodulation of $P$. tuberosus and are quickly selected against.

\section{Function of NopA.}

One possible explanation for the phenotype of the nopA mutant suggests that NopA is an external component of the secretion machine. In TTSS-possessing phytopathogens, the Hrp pili are known to be required for protein secretion (He and Jin 2003). The subunits of such pili are all small (6 to $11 \mathrm{kDa}$ ) proteins, which are secreted in relatively high molar amounts, both of which also characterize NopA (Marie et al. 2003). Comparisons of known pili subunit proteins show that there is limited homology at the primary sequence level between species. However, by using algorithms that predict protein secondary structure, it has been shown that there is some similarity between pili subunits from different bacteria (Koebnik 2001). The pili subunits are all predicted to have a very high alpha $(\alpha)$-helical content, especially at the carboxyl (C)-terminal regions. NopA was subjected to the same structural determination programs and was calculated to have a possible $\alpha$-helical content between 70 and $90 \%$, depending upon the algorithm used. In all cases, the only region not compromising $\alpha$-helices was at the amino $(\mathrm{N})$ terminus, a characteristic of other pili subunit proteins (Koebnik 2001). Thus, NopA is predicted to have the requisite secondary structural characteristics that are typical of a TTSS pilus subunit. In contrast, when the same programs were used to examine NopC, an $\alpha$-helical content of only 30 to $50 \%$ was predicted, which was located mostly at the C-terminus.

For these reasons, we used electron microscopic techniques to visualize surface appendages synthesized by NGR234. Under noninducing conditions, single NGR234 cells were seen (Fig. 5A). After induction with apigenin, multiple fibrils were

Table 1. Symbiotic properties of NGR $\triangle$ nopA

\begin{tabular}{|c|c|c|c|c|}
\hline \multirow[b]{2}{*}{ Inoculated with } & \multicolumn{4}{|c|}{ Nodules per plant tested $^{\mathrm{a}}$} \\
\hline & L. leucocephala & P. tuberosus & T. vogelii & V. unguiculata \\
\hline NGR234 & $15.7( \pm 0.4 ; 20)$ & $1.8( \pm 0.3 ; 15)$ & $21.9( \pm 0.5 ; 12)$ & $27.4( \pm 0.7 ; 13)$ \\
\hline $\mathrm{NGR} \Omega r h c N$ & $15.0( \pm 0.7 ; 16)$ & $27.5( \pm 0.8 ; 15)$ & $9.0( \pm 0.3 ; 12)$ & $23.7( \pm 0.2 ; 13)$ \\
\hline NGR $\triangle n о p A$ & $16.7( \pm 0.4 ; 16)$ & $26.2( \pm 1.1 ; 15)$ & $8.2( \pm 0.4 ; 12)$ & $18.7( \pm 0.7 ; 17)$ \\
\hline NGR $\triangle$ порA(pLAFR6) & $16.0( \pm 0.7 ; 16)$ & $22.5( \pm 0.7 ; 15)$ & $8.3( \pm 0.3 ; 12)$ & $21.8( \pm 0.5 ; 17)$ \\
\hline NGR $\Delta п о р A($ рпорА $)$ & $17.4( \pm 0.6 ; 16)$ & $25.5( \pm 1.3 ; 15)$ & $18.3( \pm 0.5 ; 12)$ & $27.2( \pm 0.8 ; 17)$ \\
\hline
\end{tabular}

${ }^{a}$ Mean numbers of nodules formed per plant are listed, followed by the standard error and the number of plants tested in parentheses. Abolition of nodulation outer protein (Nop) secretion in NGR $\Delta$ nopA led to an effect on nodulation similar to that seen with NGR $\Omega r h c N$. Introduction of pnopA into NGR $\triangle$ порA restores Nop secretion and, thus, nodulation efficiency on Tephrosia vogelii to approximately wild-type levels. Pachyrhizus tuberosus, when infected with NGR $\triangle$ nорA(pnopA), produced numbers of nodules similar to those found following inoculation with a secretion-deficient mutant. Isolation of bacteria from these nodules revealed that pnopA had been lost. Introduction of the vector only (pLAFR6) into NGR $\Delta$ nopA did not affect nodulation relative to the NGRAnopA parent strain. Deletion of nopA had little effect on the nodulation of both Leucaena leucocephala and Vigna unguiculata, two plants that show only minor responses to the Nops (Viprey et al. 1998). 
apparent on the surface of NGR234 cells that always aggregated, possibly as a result of this network of fibrils (Fig. 5B). Fibrils were not seen in the induced nopA mutant, nor were the cells aggregated (Fig. 5C). Thus, flavonoids and a functional copy of nopA are required for the synthesis of the extracellular appendages.

We then tried to isolate these surface appendages to examine their composition. NGR234, NGR $\Delta$ nopA, and NGR $\Delta$ nopA (pnopA) were grown in shaken liquid cultures with apigenin. We expected that the movement of the cells during incubation would dislodge any appendages (such as flagella or pili) from the surface. At first, the cells were removed by low-speed centrifugation. Then, macromolecular structures were collected by ultracentrifugation. The proteins isolated this way were separated using $15 \%$ SDS-PAGE and stained with silver nitrate (Fig. 6A). All three strains, including NGR $\Delta$ nopA, produced at least two proteins of approximately $30 \mathrm{kDa}$. These bands also were seen when the extractions were performed on the same strains from noninduced cultures (data not shown). The appearance of the approximately $30-\mathrm{kDa}$ proteins required neither a functional TTSS nor apigenin; therefore, they probably are unrelated to the TTSS of pNGR234a. Based upon their size, we assumed that they were flagellins, the major protein components of bacterial flagella. Rhizobial flagellins are highly conserved and the identity of the approximately $30-\mathrm{kDa}$ bands was confirmed using antiserum raised against flagellar filaments of $R$. meliloti (a generous gift of Dr. B. Scharf, University of Regensberg, Germany) (Fig. 6B). The other common band (approximately $14 \mathrm{kDa}$ ) is nonproteinaceous, because it was still present after proteinase $\mathrm{K}$ treatment of the samples (data not shown). In the preparations from NGR234, two extra bands were seen that were absent in the nopA mutant. These proteins had sizes similar to NopX (approximately $67 \mathrm{kDa}$ ) and NopA (approximately $7 \mathrm{kDa}$ ) and their identity was confirmed by immunoblotting (Fig. 6B). NopA was also seen in the surface appendage fractions from NGR $\Delta$ nopA(pnopA) but, surprisingly, NopX was absent. Because the quantity of NopA isolated was also reduced, the observed lack of NopX may be due simply to the sensitivity of detection. The antibodies raised against NopC, NopL, or NopP did not detect any proteins in the surface appendage fractions (data not shown). Molecular sieving experiments were also performed to verify that NopA and NopX are part of macromolecular complexes. The pellet fraction (after ultracentrifugation of NGR234 supernatant proteins) was passed through a Sephadex G-75 column. NopA, NopX, and the flagellins all eluted in the void volume of these columns (data not shown), implying that NopA and NopX are part of high molecular weight structures. Attempts also were made to visualize the purified macromolecular struc- tures by electron microscopy. The extracts used to prepare Figure 6 showed high levels of background staining; therefore, a sucrose gradient was used to further purify the extracts, but clear observation of pili was still difficult.

\section{DISCUSSION}

NopA is a secreted protein of NGR234 (Marie et al. 2003). Sequence comparisons of the promoter regions of rhizobial $r h c$ and nop genes led to the detection of a conserved motif, the $t$ ts box, one of which was found approximately $450 \mathrm{bp}$ upstream of nopA from NGR234 (Krause et al. 2002). We searched this region for other short ORFs and found one (nopC) that is conserved in all other rhizobial TTSS loci. nopC is found in the same relative position in USDA257 and MAFF303099, whereas a homologue is distally located in USDA110, implying that, although a rearrangement may have occurred, this ORF has been conserved in Bradyrhizobium spp. as well. Specific antibodies and mass spectrometric methods showed that NopC is also secreted via the TTSS of NGR234. Secretion requires flavonoids and a functional TTSS, but is not effected by the absence of NopL, NopP, or NopX. It seems likely that nopC encodes the $10-\mathrm{kDa}$ secreted protein, p10, observed in earlier work (Marie et al. 2003).

NopA is also a secreted component of the TTSS machine. In the absence of NopA (e.g., in the mutant NGR $\Delta$ nopA), Nop secretion is blocked. Introduction of nopA in trans restores Nop secretion. Only NopL could be detected clearly within the mutant cells, showing that secretion is blocked in NGR $\Omega r h c N$ and NGR $\Delta$ nopA. The failure to detect the other Nops may have been due to the relative insensitivity of the antibodies used. There also might be regulatory controls that prevent the transcription or translation of Nops in the absence of a functional TTSS machine, as has been proposed for other TTSSpossessing bacteria (Miller 2002). This would prevent deleterious effects on the bacterial cells due to the build up of Nops within the bacterial cells. Accumulation of NopL in NGR234 cells suggests that it is most likely the subject of slightly different regulatory controls. In contrast to other TTSS genes that are inducible, nopL is expressed even in the absence of flavonoids (Perret et al. 1999) but it is up-regulated in the presence of apigenin (W. J. Deakin, unpublished data).

The block in Nop secretion by NGR $\Delta$ nopA leads to a nodulation phenotype very similar to that of the previously characterized TTSS mutant NGR $\Omega r h c N$. Complementation of the nopA mutant restores protein secretion and efficient nodulation of $T$. vogelii. On $P$. tuberosus, however, nodules are still formed by bacteria that have lost pnopA. The empty vector is stably maintained during the nodulation assay; therefore, it
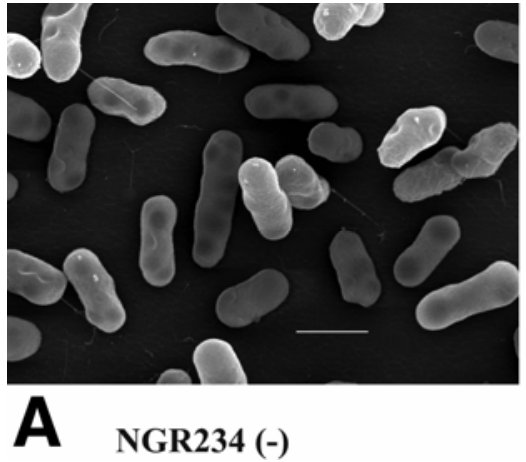
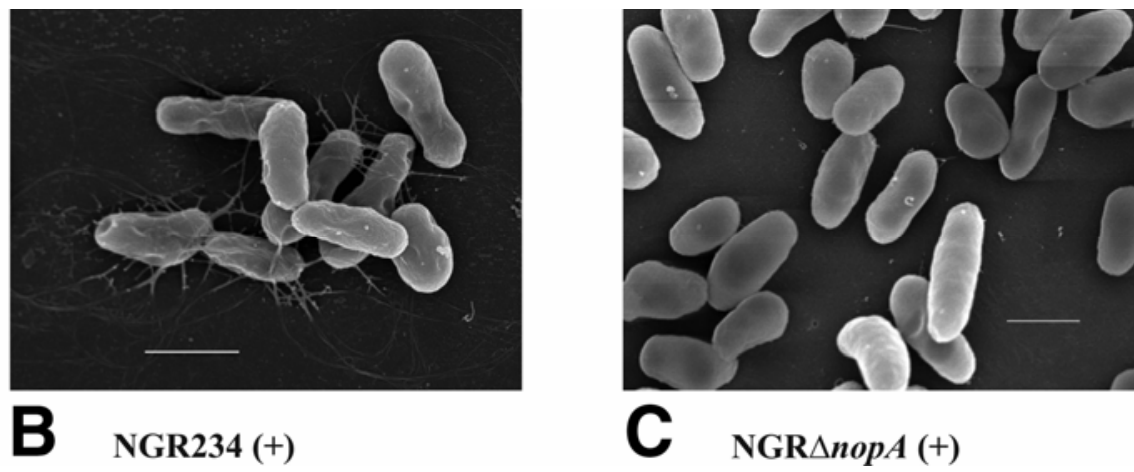

Fig. 5. Electron micrographs showing the appearance of cell surface structures after induction of NGR234 with apigenin. A, Noninduced (-) NGR234 cells, B, induced (+) NGR234 cell aggregates, and C, induced cells of NGR $\Delta$ nopA. The synthesis of the fibrillose structures required flavonoids and the presence of a functional NopA. The horizontal white bar in each image represents $1 \mu \mathrm{m}$. 
seems that $P$. tuberosus exerts a strong selective pressure for the loss of pnopA, thus preventing the secretion of Nops that are detrimental for nodule formation on this plant.

NopA shares characteristics of proteins that compose the Hrp pili of phytopathogens (He and Jin 2003). NopA is secreted in relatively high amounts (Marie et al. 2003), is small $(<10 \mathrm{kDa})$, and is predicted to have a similar secondary structure to other Hrp pili subunit proteins (Koebnik 2001). Nonpolar mutations in the genes encoding HrpA (the pilus subunit of Pseudomonas syringae) and HrpY (the pilus subunit of Ralstonia solanacearum) also abolish TTSS-dependent secretion (Roine et al. 1997b; Van Gijsegem et al. 2000). Using electron microscopy, we examined whether NGR234 could also produce TTSS-dependent pili. Fibrillar structures were seen on the surface of NGR234 cells after flavonoid induction and the synthesis of these fibrils required NopA. However, these fibrils are different from other phytopathogenic TTSS-dependent pili (Brown et al. 2001; Jin et al. 2001; Van Gijsegem et al. 2000). TTSS-dependent pili generally have a uniform width (between 6 and $8 \mathrm{~nm}$ ) and do not

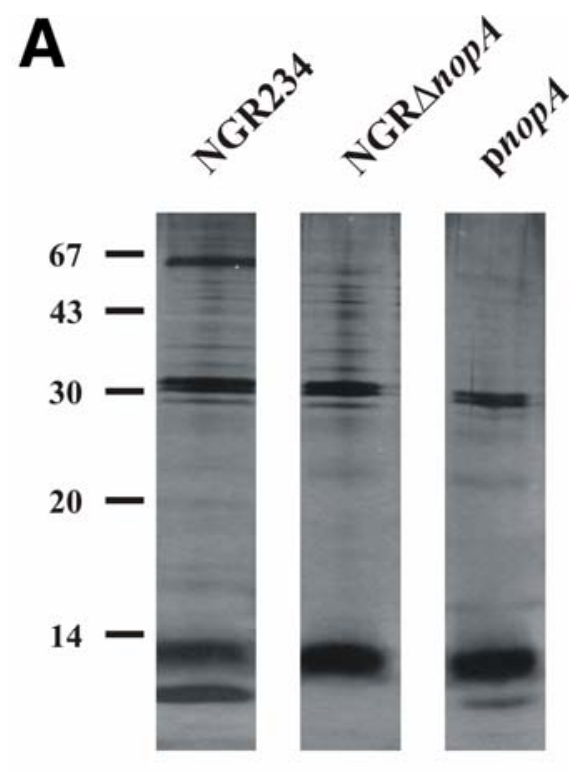

B

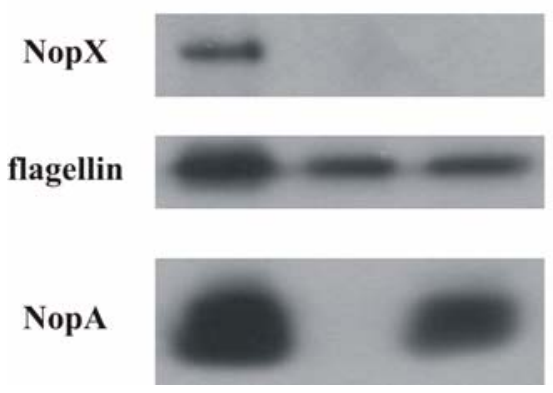

Fig. 6. Isolation and identification of the proteins associated with the surface appendages of NGR234 and derivative strains. A, Sodium dodecyl sulfate $(15 \%)$ polyacrylamide electrophoresis gels stained with silver nitrate showing the composition of the surface appendages from induced cells of NGR234, NGR $\triangle$ nopA, and NGR $\Delta$ nopA(pnopA) (labeled as pnopA). Sizes (in $\mathrm{kDa}$ ) of the molecular weight markers are shown to the left of the figure. B, Immunological characterization of these bands. Probing with anti-NopX serum showed the approximately $67-\mathrm{kDa}$ band of NGR234 to be NopX. The common bands at approximately $30 \mathrm{kDa}$ all cross-reacted with antibodies raised against purified flagellar filaments of Rhizobium meliloti. Finally, the low molecular weight band seen only with NGR234 and NGRAnopA (pnopA) strongly bound to the anti-NopA serum. branch, whereas the NGR234 images show a highly branched network of fibrils of variable width (Fig. 5B). Flavonoid-induced NGR234 cells were never observed singly, suggesting that these fibrils may also cause the cells to aggregate. These fibrillar structures are reminiscent of the cellulose fibrils seen on the surface of Agrobacterium tumefaciens cells during attachment to plant cells: such fibrils also cause aggregation of the A. tumefaciens cells (Matthysse et al. 1981). Whatever the nature of the NGR234 fibrils, a functional NopA protein and flavonoids are required for their synthesis. Perhaps TTSS-dependent pili (predominantly composed of NopA) could be synthesized but then covered with exopolysaccharide (EPS) that NGR234 is known to produce in large amounts (Gray et al. 1991). This would explain the increased width and branching seen in the NGR234 appendages. The EPS may help stabilize the pili or even mask them from recognition by the plant. Alternatively, the fibrils seen under the electron microscope could result from independently produced pili and EPS that associate with the cells as they are dried onto the grids. To try to circumvent this problem, we used a mutant of NGR234 that completely lacks EPS. This strain (ANU2823) has a mutation within exoY, which encodes an enzyme involved in the initial steps of EPS synthesis (Gray et al. 1990). Although this strain secretes NopA, TTSS-dependent surface appendages could not be isolated from it (data not shown). Thus, perhaps EPS is required to stabilize pili.

Preparations of surface appendages from NGR234 cells contain two Nops (NopA and NopX) that seem to be components of the external macromolecular structures. The detection of NopA supports our contention that it could be the subunit of the TTSS-dependent pilus. The presence of NopX in the preparations of surface appendages is intriguing, however. Although the isolation of surface structures from $P$. syringae and Ralstonia solanacearum also showed other unidentified proteins (Roine et al. 1997b; Van Gijsegem et al. 2000), only HrpA or HrpY have been detected in the Hrp pili of $P$. syringae and RALSTONIA solanacearum, respectively (He and Jin 2003). Furthermore, when HrpA was purified from Hrp pili, it was able to repolymerize into pili in the absence of other proteins (Roine et al. 1997a). NopX does not have any of the properties of previously characterized TTSS-dependent pili subunits. Indeed, it is thought to be a translocatory protein that forms a pore in the plant cell membrane to facilitate the transit of effector proteins (Marie et al. 2003). Most probably, effectors transit through the pilus and then through the translocon pore (Büttner and Bonas 2002). Could NopA and NopX interact to form a continuous structure, which thus causes NopX to coextract with NopA? Alternatively, because translocatory proteins have been shown to polymerize to form this pore (Schoehn et al. 2003), it is possible that a multimeric NopX complex also is pelleted during ultracentrifugation. Surface appendages isolated from NGR234 did not contain any of the other identified Nops.

Recently, it has been shown that USDA257 assembles pili in a TTSS- (and flavonoid-) dependent manner (Krishnan et al. 2003). Isolation of the surface appendages and subsequent SDS-PAGE analysis showed that one of the major components is a small protein called Nop7 (i.e., with a molecular weight of $7 \mathrm{kDa}$ ). USDA257 and NGR234 share remarkably similar TTSS loci (comparison of NopA from each Rhizobium strain shows only one [conserved] amino acid difference) (Marie et al. 2003); therefore, it is very likely that Nop7 is NopA.

NGR234 synthesizes extracellular appendages in a flavonoid- and TTSS-dependent manner. NopA is the major component of these appendages and is also the first Nop shown to be essential for the secretion of the other Nops. Thus 
NGR234, like other TTSS-possessing bacteria, produces secreted proteins, not all of which function within the eukaryotic host cell.

\section{MATERIALS AND METHODS}

\section{Microbiological techniques.}

Bacterial strains and plasmids used in this study are listed in Table 2. Escherichia coli strains were grown in Luria-Bertani medium at $37^{\circ} \mathrm{C}$ (Sambrook et al. 1989). Rhizobium strains were grown at $27^{\circ} \mathrm{C}$ in either complete (TY) (Beringer 1974) or minimal media (RMS, using succinate as a carbon source at a final concentration of $12 \mathrm{mM}$ ) (Broughton et al. 1986). When flavonoid induction was required, apigenin was added to a final concentration of $10^{-6} \mathrm{M}$. Antibiotics were added to the media at the following final concentrations: ampicillin (Ap), $50 \mu \mathrm{g} \mathrm{ml}^{-1}$; kanamycin $(\mathrm{Km}), 100 \mu \mathrm{g} \mathrm{ml}^{-1}$; rifampicin (Rif), $100 \mu \mathrm{g} \mathrm{ml}^{-1}$; spectinomycin (Sp), $50 \mu \mathrm{g} \mathrm{ml}^{-1}$; and tetracycline (Tc), $10 \mu \mathrm{g} \mathrm{ml}^{-1}$. Plasmids were mobilized from $E$. coli strain DH5 $\alpha$ to Rhizobium strains by triparental matings using the helper plasmid pRK2013 (Figurski and Helinski 1979).

\section{Mutagenesis of nopA.}

Standard molecular cloning techniques were carried out as described by Sambrook and associates (1989). The in-frame deletion of nopA $\left(\right.$ nop $\left.A_{\Delta 4-71}\right)$ was generated in vitro using a polymerase chain reaction (PCR)-based strategy (Higuchi 1989). A 1.1-kb ApaI-SalI fragment of pXB740 containing nopA was subcloned into pBluescript $\mathrm{KS}+$, creating pBDG36. Two oligonucleotide primers were designed specific to the $5^{\prime}$ and $3^{\prime}$ ends of nopA: nopA deletion start, 5'-GCCGTTAACTT TAGACATGTCATTTCC-3'; and nopA deletion end, 5'-GCG $\underline{G}$ TTAACTGATGCGGATGGGGCTCT-3'.

A PCR reaction using these primers and pBDG36 as template resulted in a PCR product deleted of nopA. This product was digested with $\mathrm{HpaI}$ (sites underlined in primers) and then circularized to create pBDG38. This plasmid was sequenced to verify accuracy of the PCR and the nopA deletion. ApaI and SalI were used to excise the 900-bp fragment lacking nopA which was subcloned into the rhizobial suicide vector $\mathrm{pK} 18$ mobsacB (Schäfer et al. 1994), creating pBDG43. Triparental matings were used to transfer pBDG43 into NGR234. Double recombination was selected by plating bacteria onto RMS plates containing 5\% sucrose. Putative mutants were confirmed by probing Southern blots of restricted genomic DNA using standard procedures (Chen and Kuo 1993; Sambrook et al. 1989). To complement NGR $\Delta n o p A$, a 2.4-kb HindIII-XbaI fragment of pXB740 was cloned into pLAFR6, creating pnopA.

\section{Computer analysis of DNA proteins.}

ORFs within the nopA locus were initially identified using DNAStrider. Homology searches were performed using the BLAST suite of programs. The algorithms used to predict the secondary structure of NopA are described by Koebnik (2001). The alignment of the NopC proteins was made using ClustalW at EMBnet.

\section{Purification and analysis of secreted proteins.}

Secreted proteins were prepared as described by Marie and associates (2003). Briefly, Rhizobium strains were grown in $100 \mathrm{ml}$ of RMS for $40 \mathrm{~h}$ in the presence of apigenin to a final optical density at $600 \mathrm{~nm}$ of approximately 0.8 . Cells were removed by two successive centrifugations at $5,000 \times g$ for 20 min. To precipitate supernatant proteins, ammonium sulfate (60\% wt/vol final concentration) was added to the supernatants cleared of bacteria. Samples were desalted using Sephadex G25-containing columns (Amersham Biosciences, Uppsala, Sweden). To lyse the bacteria, the cell pellet resulting from the first centrifugation was resuspended in $1 \mathrm{ml}$ of $\mathrm{H}_{2} 0,200-\mu \mathrm{l}$ portions were taken, and the cells were collected by centrifugation. The pellets were resuspended in $200 \mu \mathrm{l}$ of BugBuster reagent (Novagen, Darmstadt, Germany) and the cells left to lyse for $20 \mathrm{~min}$ at room temperature. Centrifugation was repeated to remove cellular debris and the supernatant was used as the lysate fraction. Protein concentrations were determined using the Bio-Rad protein assay kit (Bio-Rad Laboratories, Hercules, CA, U.S.A.).

For 2D-SDS-PAGE, $100 \mu \mathrm{g}$ of extracellular proteins were dissolved in solubilization solution (8 M urea, 4\% CHAPS, 5 $\mathrm{mM}$ dithioerythritol [DTE], $0.5 \%$ IPG buffer, $\mathrm{pH} 3$ to 10 [Amersham], and $0.1 \%$ bromophenol blue). Solubilized sam-

Table 2. Bacterial strains and plasmids used in this study

\begin{tabular}{|c|c|c|}
\hline Strains & Characteristics $^{\mathbf{a}}$ & Reference, source \\
\hline $\begin{array}{l}\text { Escherichia coli } \\
\text { DH5 }\end{array}$ & 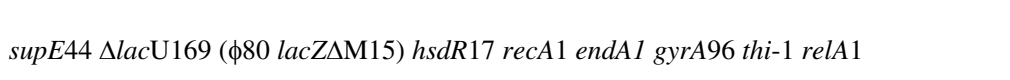 & BRL, Bethesda, MD, U.S.A. \\
\hline Rhizobium strains & & \\
\hline NGR234 & Broad-host-range bacterium isolated from nodules of Lablab purpureus, Rif $^{\mathrm{r}}$ & Stanley et al. 1988 \\
\hline NGR $\Omega r h c N$ & $\begin{array}{l}\text { NGR234 derivative containing an } \Omega \text { cassette inserted in to the EcoRI site of } r h c N \text {, } \\
\text { Rifr }^{\mathrm{r}}, \mathrm{Sp}^{\mathrm{r}}\end{array}$ & Viprey et al. 1998 \\
\hline NGR $\Omega$ nopL & $\begin{array}{l}\text { NGR234 derivative containing an } \Omega \text { cassette inserted in to the EcoRV site of } n o p L \text {, Rif } \\
\mathrm{Km}^{\mathrm{r}}\end{array}$ & Marie et al. 2003 \\
\hline NGR $\triangle$ порP & $\begin{array}{l}\text { NGR234 derivative in which the } 1,128 \text {-bp XhoHI internal fragments of nopP were } \\
\text { replaced by an } \Omega \text { cassette, } \operatorname{Rif}^{\mathrm{r}}, \mathrm{Sp}^{\mathrm{r}}\end{array}$ & Ausmees et al. 2004 \\
\hline NGR $\Delta n о p X$ & $\begin{array}{l}\text { NGR234 derivative in which the 552-bp BamHI internal fragment of nopX was replaced } \\
\text { by an } \Omega \text { cassette, } \text { Rif }^{\mathrm{r}}, \mathrm{Sp}^{\mathrm{r}}\end{array}$ & Marie et al. 2003 \\
\hline $\begin{array}{l}\text { NGR } \Delta n o p A \\
\text { Plasmids }\end{array}$ & NGR234 derivative with nopA deleted, Rif $^{\mathrm{r}}$ & This work \\
\hline pBluescript II KS+ & High copy number ColE1-based phagemid, $\mathrm{Ap}^{\mathrm{r}}$ & Stratagene, La Jolla, CA, U.S.A. \\
\hline pXB740 & Lorist 2 derivative containing the $\mathrm{y} 4 \mathrm{yE}$ to $\mathrm{y} 4 \mathrm{aE}$ region of $\mathrm{pNGR} 234 a, \mathrm{Km}^{\mathrm{r}}$ & Perret et al. 1991 \\
\hline pBDG36 & $\begin{array}{l}\text { pBluescript KS+ derivative carrying an ApaI-SalI fragment of pXB740 containing nopA, } \\
\mathrm{Ap}^{\mathrm{r}}\end{array}$ & This work \\
\hline pBDG38 & As pBDG36 but with nopA deleted by PCR, Ap ${ }^{\mathrm{r}}$ & This work \\
\hline pK18mobsacB & Suicide vector for rhizobia, $\mathrm{Km}^{\mathrm{r}}$ & Schäfer et al. 1994 \\
\hline pBDG43 & pK18mobsacB derivative carrying ApaI-SalI fragment of pBDG38 (nopA deleted), $\mathrm{Km}^{\mathrm{r}}$ & This work \\
\hline pLAFR6 & Broad host vector containing transcriptional terminators flanking the cloning sites, $\mathrm{Tc}^{\mathrm{r}}$ & D. Dahlbeck and B. Staskawicz \\
\hline рпорА & A pLAFR6 derivative containing a 2.4-kb HindIII-XbaI fragment of pXB740, Tc $\mathrm{r}^{\mathrm{r}}$ & This work \\
\hline
\end{tabular}

${ }^{\mathrm{a}} \mathrm{Rif}=$ rifampicin, $\mathrm{Sp}=$ spectinomycin, $\mathrm{Km}=$ kanamycin, $\mathrm{Ap}=$ ampicillin, and $\mathrm{Tc}=$ tetracycline. 
ples were applied to $18-\mathrm{cm}, \mathrm{pH} 3$ to $10 \mathrm{NL}$ Immobiline (IPG) DryStrips (Amersham) and subjected to isoelectrical focusing (IEF) at $18^{\circ} \mathrm{C}$ to reach 100,000 volt-hours using an IPGphor IEF unit (Amersham). Following IEF, the gel strips were equilibrated for $12 \mathrm{~min}$ in Tris-HCI buffer $(0.5 \mathrm{M}, \mathrm{pH} 8.5)$ containing $6 \mathrm{M}$ urea, $30 \%$ glycerol, $2 \% \mathrm{SDS}$, a trace of bromophenol blue, and 2\% DTE, followed by a second equilibration using $2.5 \%$ iodoacetamide instead of DTE for $10 \mathrm{~min}$. The equilibrated IPG strips were then subjected to SDS-PAGE $(15 \%)$ in the second dimension on a PROTEAN II XL cell (Bio-Rad). Proteins spots were then visualized by a silver staining procedure that is compatible with mass spectrometry (Ausubel et al. 1991). The spot, based upon its size and pI, which was suspected of being NopC was cut from the gel and was subjected to peptide mass fingerprint analysis (using the Swiss-2D service, Geneva, Switzerland).

For immunostaining, proteins were transferred from SDSPAGE gels onto Millipore Immobilon polyvinylidene difluoride membranes by electroblotting as described by Ausubel and associates (1991). Protein-primary antibody complexes were visualized using horseradish peroxidase-labeled antirabbit antibodies and ECL detection reagents (Amersham). Broad-range prestained markers from Bio-Rad (208, 115, $79.5,49.5,34.8,28.3,20.4$, and $7.2 \mathrm{kDa}$ ) were used as protein standards.

\section{Antibodies.}

Antisera to NopC were generated by immunizing rabbits with synthesized peptides designed from the sequence of NopC: N-TGQPPRDSGGPSSGHN and N-MADADEAMAE TEEDA. Peptides were coupled to carrier proteins prior to immunization according to the manufacturer's protocols (Eurogentec, Herstal, Belgium). Production of the antisera against NopA, NopL, NopP, and NopX has been described previously (Ausmees et al. 2004; Marie et al. 2003). The anti-NopX antibody cross-reacted nonspecifically with two smaller secreted proteins, one of which was used as a loading control in Figures 3B and 4. The appearance of these bands is independent of a functional TTSS.

\section{Purification of surface appendages.}

To isolate macromolecular surface appendages, cells were grown in YEM media (Vincent 1970) for $48 \mathrm{~h}$ at $27^{\circ} \mathrm{C}$. The cells were removed by low-speed centrifugation and supernatants subjected to ultracentrifugation at $10^{\circ} \mathrm{C}$ for 90 minutes (using a Sorvall type 40 rotor at $90,000 \times g$ ) to pellet macromolecular structures. The pellets were resuspended in $10 \mathrm{mM}$ Tris- $\mathrm{HCl}$ ( $\mathrm{pH} 8.0$ ). Proteins were separated by electrophoresis on $15 \%$ SDS-PAGE gels and stained with silver nitrate (Ausubel et al. 1991). Low-range molecular weight markers from Amersham (94, 67, 43, 30, 20.1, and $14.4 \mathrm{kDa}$ ) were used as protein standards.

\section{Electron microscopy.}

Cold-field emission-scanning electron microscopy was performed according to Krishnan and associates (2003). Briefly, cells were grown in YEM broth with or without flavonoids for $48 \mathrm{~h}$ at $27^{\circ} \mathrm{C}$. The cells were collected, applied to poly-L-lysinecoated cover-slips, and allowed to dry before being fixed using $2 \%$ glutaraldehyde and $2 \%$ paraformaldehyde. The cells were stained with $1 \%$ osmium tetroxide and examined with a $\mathrm{S}$ 4700 cold field emission scanning electron microscopy (Hitachi, Tokyo).

\section{Plant material and assays.}

Seed sources are listed in Pueppke and Broughton (1999). Nodulation tests were performed in Magenta jars as described by Viprey and associates (1998). To re-isolate rhizobia from nodules, 100 nodules were taken from each nodulation experiment. Nodules were surface-sterilized in $70 \%$ ( $\mathrm{vol} / \mathrm{vol})$ ethanol, rinsed in sterile $\mathrm{H}_{2} \mathrm{O}$, and then sliced in half with a sterile razor blade. The open face of each nodule was streaked onto TY agar containing rifampicin and incubated at $27^{\circ} \mathrm{C}$ for 3 to 5 days. Single colonies then were tested for their antibiotic resistance or sensitivity.

\section{ACKNOWLEDGMENTS}

This work was supported by the Fonds National de la Recherche Scientifique (Project 31-63893.00), and the Université de Genève. We wish to thank Y.-Y. Aung and D. Gerber for their unstinting help, B. Scharf (University of Regensberg, Germany) for the gift of the $R$. meliloti flagellin antibody, and C. Staehelin (University of Geneva, Switzerland) for proofreading the manuscript.

\section{LITERATURE CITED}

Ausmees, N., Kobayashi, H., Deakin, W. J., Marie, C., Krishnan, H. B. Broughton, W. J., and Perret, X. 2004. Characeterisation of NopP, a type III secreted effector of Rhizobium sp. NGR234. J. Bacteriol. 186:4774-4780.

Ausubel, F. M., Brent, R., Kingston, R. E., Moore, D. D., Seidman, J. G., Smith, J. A., and Struhl, K. 1991. Current Protocols in Molecular Biology. John Wiley \& Sons, Inc, New York.

Bartsev, A. V., Boukli, N. M., Deakin, W. J., Staehelin, C., and Broughton, W. J. 2003. Purification and phosphorylation of the effector protein NopL from Rhizobium sp. NGR234. FEBS (Fed. Eur. Biol. Soc.) Lett. 554:271-274.

Bartsev, A. V., Deakin, W. J., Boukli, N. M., McAlvin, C. B., Stacey, G., Malnoë, P., Broughton, W. J., and Staehelin, C. 2004. NopL, an effector protein of Rhizobium sp. NGR234 thwarts activation of plant defence reactions. Plant Physiol. 134:871-879.

Beringer, J. E. 1974. R-factor transfer in Rhizobium leguminosarum. J. Gen. Microbiol. 84:188-198.

Broughton, W. J., Wong, C.-H., Lewin, A., Samrey, U., Myint, H., Meyer z. A., H., Dowling, D. N., and Simon, R. 1986. Identification of Rhizobium plasmid sequences involved in recognition of Psophocarpus, Vigna, and other legumes. J. Cell Biol. 102:1173-1182.

Broughton, W. J., Jabbouri, S., and Perret, X. 2000. Keys to symbiotic harmony. J. Bacteriol. 182:5641-5652.

Brown, I., Mansfield, J. W., Taira, S., Roine, E., and Romantschuk, M. 2001. Immunocytochemical localization of HrpA and HrpZ supports a role for the Hrp pilus in the transfer of effector proteins from Pseudomonas syringae pv. tomato across the host plant cell wall. Mol. PlantMicrobe Interact. 14:394-404.

Büttner, D., and Bonas, U. 2002. Getting across-bacterial type III effector proteins on their way to the plant cell. EMBO (Eur. Mol. Biol. Organ.) J. 21:5313-5322.

Büttner, D., and Bonas, U. 2003. Common infection strategies of plant and animal pathogenic bacteria. Curr. Opin. Plant Biol. 6:312-319.

Chen, W.-P., and Kuo, T.-T. 1993. A simple and rapid method for the preparation of gram-negative bacterial genomic DNA. Nucleic Acids Res. 21:2260.

Cornelis, G. R., and Van Gijsegem, F. 2000. Assembly and function of type III secretory systems. Annu. Rev. Microbiol. 54:735-774.

Dale, C., Young, S. A., Haydon, D. T., and Welburn, S. C. 2001. The insect endosymbiont Sodalis glossinidius utilizes a type III secretion system for cell invasion. Proc. Natl. Acad. Sci. U.S.A. 98:1883-1888.

Figurski, D. H., and Helinski, D. R. 1979. Replication of an origin-containing derivative of plasmid RK2 dependent on a plasmid function provided in trans. Proc. Natl. Acad. Sci. U.S.A. 76:1648-1652.

Freiberg, C., Fellay, R., Bairoch, A., Broughton, W. J., Rosenthal, A., and Perret, X. 1997. Molecular basis of symbiosis between Rhizobium and legumes. Nature 387:394-401.

Göttfert, M., Röthlisberger, S., Kündig, C., Beck, C., Marty, R., and Hennecke, H. 2001. Potential symbiosis-specific genes uncovered by sequencing a 410-kilobase DNA region of the Bradyrhizobium japonicum chromosome. J. Bacteriol. 183:1405-1412.

Gray, J. X., Djordjevic, M. A., and Rolfe, B. G. 1990. Two genes that regulate exopolysaccharide production in Rhizobium sp. strain NGR234: DNA sequences and resultant phenotypes. J. Bacteriol. 172:193-203.

Gray, J. X., Zhan, H. J., Levery, S. B., Battisti, L., Rolfe, B. G., and Leigh, J. A. 1991. Heterologous exopolysaccharide production in Rhizobium 
sp. strain NGR234 and consequences for nodule development. J. Bacteriol. 173:3066-3077.

He, S. Y. 1998. Type III protein secretion systems in plant and animal pathogenic bacteria. Annu. Rev. Phytopathol. 36:363-392.

He, S. Y., and Jin, Q. 2003. The Hrp pilus: learning from flagella. Curr. Opin. Microbiol. 6:15-19.

Higuchi, R. 1989. Using PCR to engineer DNA. Pages 61-70 in: PCR Technology. Principles and Applications for DNA Amplification. H. A. Erlich, ed. Stockton Press, New York.

Hueck, C. J. 1998. Type III protein secretion systems in bacterial pathogens of animals and plants. Microbiol. Mol. Biol. Rev. 62:379-433.

Jin, Q., and He, S.-Y. 2001. Role of the Hrp pilus in type III protein secretion in Pseudomonas syringae. Science 294:2256-2258.

Jin, Q., Hu, W., Brown, I., McGhee, G., Hart, P., Jones, A. L., and He, S. Y. 2001. Visualization of secreted Hrp and Avr proteins along the Hrp pilus during type III secretion in Erwinia amylovora and Pseudomonas syringae. Mol. Microbiol. 40:1129-1139.

Kobayashi, H., Graven, Y. N., Broughton, W. J., and Perret, X. 2004. Flavonoids induce temporal shifts in gene-expression of nod-box controlled loci in Rhizobium sp. NGR234. Mol. Microbiol. 51:335-347.

Koebnik, R. 2001. The role of bacterial pili in protein and DNA translocation. Trends Microbiol. 9:586-590.

Krause, A., Doerfel, A., and Göttfert, M. 2002. Mutational and transcriptional analysis of the type III secretion systems of Bradyrhizobium japonicum. Mol. Plant-Microbe Interact. 15:1228-1235.

Krishnan, H. B., Lorio, L., Kim, W. S., Jiang, G., Kim, K. Y., DeBoer, M. and Pueppke, S. G. 2003. Extracellular proteins involved in soybean cultivar-specific nodulation are associated with pilus-like surface appendages and exported by a type III protein secretion system in $\mathrm{Si}$ norhizobium fredii USDA257. Mol. Plant-Microbe Interact. 16:617625

Li, C.-M., Brown, I., Mansfield, J. W., Stevens, C., Boureau, T., Romantschuk, M., and Taira, S. 2002. The Hrp pilus of Pseudomonas syringae elongates from its tip and acts as a conduit for translocation of the effector protein HrpZ. EMBO (Eur. Mol. Biol. Organ.) J. 21:19091915.

Marie, C., Broughton, W. J., and Deakin, W. J. 2001. Rhizobium type III secretion systems: legume charmers or alarmers? Curr. Opin. Plant Biol. 4:336-342.

Marie, C., Deakin, W. J., Viprey, V., Kopcinska, J., Golinowski, W., Krishnan, H. B., Perret, X., and Broughton, W. J. 2003. Characterization of Nops, nodulation outer proteins, secreted via the type III secretion system of NGR234. Mol. Plant-Microbe Interact. 16:743-751.

Matthysse, A. G., Holmes, K. V., and Gurlitz, R. H. 1981. Elaboration of cellulose fibrils by Agrobacterium tumefaciens during attachment to carrot cells. J. Bacteriol. 145:583-595.

Miller, V. L. 2002. Connections between transcriptional regulation and type III secretion? Curr. Opin. Microbiol. 5:211-215.
Perret, X., Broughton, W. J., and Brenner, S. 1991. Canonical ordered cosmid library of the symbiotic plasmid of Rhizobium species NGR234. Proc. Natl. Acad. Sci. U.S.A. 88:1923-1927.

Perret, X., Freiberg, C., Rosenthal, A., Broughton, W. J., and Fellay, R. 1999. High-resolution transcriptional analysis of the symbiotic plasmid of Rhizobium sp. NGR234. Mol. Microbiol. 32:415-425.

Perret, X., Staehelin, C., and Broughton, W. J. 2000. Molecular basis of symbiotic promiscuity. Microbiol. Mol. Biol. Rev. 64:180-201.

Pueppke, S. G., and Broughton, W. J. 1999. Rhizobium sp. strain NGR234 and $R$. fredii USDA257 share exceptionally broad, nested host ranges. Mol. Plant-Microbe Interact. 12:293-318.

Roine, E., Saarinen, J., Kalkkinen, N., and Romantschuk, M. 1997a. Purified HrpA of Pseudomonas syringae pv. tomato DC3000 reassembles into pili. FEBS (Fed. Eur. Biol. Soc.) Lett. 417:168-172.

Roine, E., Wei, W., Yuan, J., Nurmiaho-Lassila, E. L., Kalkkinen, N., Romantschuk, M., and He, S. Y. 1997b. Hrp pilus: an hrp-dependent bacterial surface appendage produced by Pseudomonas syringae pv. tomato DC3000. Proc. Natl. Acad. Sci. U.S.A. 94:3459-3464.

Sambrook, J., Fritsch, E. F., and Maniatis, T. 1989. Molecular Cloning: A Laboratory Manual, 2nd ed. Cold Spring Harbor Laboratory Press, Cold Spring Harbor, NY, U.S.A.

Schäfer, A., Tauch, A., Jager, W., Kalinowski, J., Thierbach, G., and Puhler, A. 1994. Small mobilizable multi-purpose cloning vectors derived from the Escherichia coli plasmids pK18 and pK19: selection of defined deletions in the chromosome of Corynebacterium glutanicum. Gene 145:69-73.

Schoehn, G., Di Guilmi, A. M., Lemaire, D., Attree, I., Weissenhorn, W., and Dessen, A. 2003. Oligomerization of type III secretion proteins PopB and PopD precedes pore formation in Pseudomonas. EMBO (Eur. Mol. Biol. Organ.) J. 22:4957-4967.

Stanley, J., Dowling, D. N., and Broughton, W. J. 1988. Cloning of hemA from Rhizobium sp. NGR234 and symbiotic phenotype of a genedirected mutant in diverse legume genera. Mol. Gen. Genet. 215:32-37.

Van Gijsegem, F., Vasse, J., Camus, J. C., Marenda, M., and Boucher, C. 2000. Ralstonia solanacearum produces Hrp-dependent pili that are required for PopA secretion but not for attachment of bacteria to plant cells. Mol. Microbiol. 36:249-260.

Vincent, J. M. 1970. A Manual for the Practical Study of Root-Nodule Bacteria. Blackwell Scientific, Oxford

Viprey, V., Del Greco, A., Golinowski, W., Broughton, W. J., and Perret, X 1998. Symbiotic implications of type III protein secretion machinery in Rhizobium. Mol. Microbiol. 28:1381-1389.

\section{AUTHOR-RECOMMENDED INTERNET RESOURCE}

National Center for Biotechnology Information BLAST website: www.ncbi.nlm.nih.gov/BLAST/ 